\title{
Clubinho de Engenharia: uma Abordagem Lúdica para o Ensino de Ciências e Matemática
}

Victória da Silva Braga - victoriabraga@id.uff.br

Universidade Federal Fluminense, Engenharia Mecânica, TEM

Rua Passo da Pátria, 156

24210-240 - Niterói - Rio de Janeiro

Calebe Vitor de Moura Meira - calebemoura@id.uff.br

Universidade Federal Fluminense, Engenharia Mecânica, TEM

Rua Passo da Pátria, 156

24210-240 - Niterói - Rio de Janeiro

Danilo Cardoso Rangel - danilorangel@id.uff.br

Universidade Federal Fluminense, Engenharia Mecânica, TEM

Rua Passo da Pátria, 156

24210-240 - Niterói - Rio de Janeiro

João Pedro Rodriguesdos Santos -jp_rodrigues@id.uff.br

Universidade Federal Fluminense, Engenharia Mecânica, TEM

Rua Passo da Pátria, 156

24210-240 - Niterói - Rio de Janeiro

Fabiana Rodrigues Leta-fabianaleta@id.uff.br

Universidade Federal Fluminense, Engenharia Mecânica, TEM

Rua Passo da Pátria, 156

24210-240 - Niterói - Rio de Janeiro

Resumo: A dificuldade da transição dos alunos para o ensino fundamental II é algo bem evidente e que se busca ser amenizada com o projeto Clubinho de Engenharia. Os alunos do Programa de Educação Tutorial de Engenharia Mecânica da Universidade Federal Fluminense visam, através desta atividade, ao aumento do interesse dos alunos em aprender e estudar os conteúdos ensinados em sala de aula. A metodologia utilizada foi a de introduzir atividades práticas que envolvessem as disciplinas curriculares de ciências e matemática para que os alunos compreendessem e absorvessem melhor tais conteúdos, de uma forma lúdica e mais amigável e próxima da vida dos alunos de forma a atraí-los para o estudo. As oficinas visam criar um maior interesse nas matérias e deixá-los mais animados quanto ao ingresso em uma nova fase da vida acadêmica. E como consequência, tem-se a redução da defasagem e dificuldade dos alunos nas disciplinas correspondentes.

Palavras-chave: Extensão. Ciências exatas. Ciências da natureza. Ensino Fundamental. Programa de Educação Tutorial. 


\section{INTRODUÇÃO}

O projeto "Clubinho de Engenharia" foi desenvolvido pelo Programa de Educação Tutorial da Engenharia Mecânica da Universidade Federal Fluminense - UFF em parceria com o Colégio Estadual Doutor Rodolpho Siqueira (CEDROS) no decorrer dos anos de 2018 e 2019. A iniciativa de criar uma oficina que ajudasse alunos do ensino fundamental II de uma escola estadual a ingressarem em um novo ciclo, veio da necessidade de melhorar e otimizar o aprendizado das crianças a fim de motivá-las a uma melhor rotina de estudos e transformar matérias dadas em sala em algo mais atrativo.

Dados do Ideb (Índice de Desenvolvimento da Educação Básica) 2017 mostraram que no $6^{\circ}$ ano do ensino fundamental (primeira série existente na escola) apresentava um baixo rendimento no qual, em torno de, $40 \%$ da turma não conseguia notas suficientes para prosseguir à série seguinte. Resultados que fizeram a escola ficar alerta e ao entrar em contato com o PETMEC comunicaram tal defasagem. Os estudantes da UFF criaram o projeto a fim de intervir e modificar esses resultados.

Existem quase duas escolas de anos iniciais (116,3 mil) para cada escola de anos finais do ensino fundamental (62,5 mil) (INEP, 2017), segundo dados do MEC em 2017. Esses números demonstram a importância em se ter um bom trabalho e ótimos resultados desde os primeiros anos de ensino escolar, a fim de valorizar o ensino e estimular as crianças a permanecerem nos colégios.

O Clubinho de Engenharia tem como base a conformidade explicitada pelo artigo 207 da Constituição Federal de 1998 que diz "As universidades gozam de autonomia didáticocientífica, administrativa e de gestão financeira e patrimonial, e obedecerão ao princípio de indissociabilidade entre ensino, pesquisa e extensão." Além de reforçar os conceitos aprendidos em sala de aula através de atividades lúdicas, o projeto objetiva ajudar a motivar as crianças para que continuem indo à escola e, consequentemente, o colégio tenha uma diminuição na defasagem escolar durante o ensino fundamental.

\section{METODOLOGIA}

A metodologia apresentada foi baseada em primeiro fazer observações a respeito da situação de aprendizado das crianças, através de interações com os alunos e buscando informações com os professores e a diretoria. Após, a análise da situação, foi discutida uma proposta de aprendizado e organização, que fosse aplicável na realidade da escola e que fosse capaz de fornecer dados sobre o resultado.

\subsection{Situação}

Durante as primeiras visitas à escola, notou-se a gama de desinteresse em sala de aula, dificuldades de aprendizado dos alunos e didática falha do corpo docente do ensino público, foi estudado outras possíveis causas dos empecilhos educativos das crianças na tentativa de encontrar uma solução que conseguisse incentivar a melhoria do rendimento acadêmico delas. Os professores não possuíam um cronograma bem elaborado para a continuidade das aulas e havia certa lentidão quanto ao conteúdo passado ao longo do ano (em 2018, um dos professores ficou um semestre inteiro explicando apenas um conteúdo), que dificultavam tanto a proposta do programa quanto o ensino estudantil.

Além disso, foi observado empecilhos na vida dos alunos, agora em caráter familiar: muitas crianças não tinham alicerce familiar forte, não tinham incentivo ao estudo vindo de casa e não 
conseguiam enxergar um futuro melhor, proporcionado pela vida acadêmica atual (especialmente as meninas que aparentavam já dividir seu tempo em, além de problemas familiares, questões amorosas). Questões de condições financeiras mais precárias também foram observadas, visto que algumas crianças tinham no colégio a refeição principal.

Assim, muitas crianças iam para as aulas de reforço na tentativa de fugirem da sua realidade, mas sem vontade de aprender. A falta de interesse pela escola é um dos principais fatores para o afastamento dos jovens das mesmas. Eckstein e Wolpin (1999) mostram que alunos sem esperança de melhores condições de vida provenientes dos estudos possuem chance maior de abdicar da escola.

\subsection{Proposta}

Na elaboração foi decidido frequentar a escola alvo a cada 15 dias, com intenção de facilitar o ensino de matemática e ciências naturais através de atividades lúdicas preparadas para o grupo de crianças do $6^{\circ}$ do Ensino Fundamental (Santos, A. H. dos, et al., 2019). A Direção do colégio permitiu a realização do planejamento do Clubinho, contanto que fossem atendidos os cronogramas dos educadores e que não fosse feito no período das aulas, que ocorriam no horário vespertino.

No intuito de apresentar soluções para os problemas observados, foi estabelecido que as aulas que seriam realizadas deveriam ser mais práticas, saindo da trivialidade escolar, adotando o "Aprender Brincando", que consiste em transformar o conteúdo acadêmico em jogos ou atividades dinâmicas (Silva, J. N., 2014). Em cada aula era adotado uma brincadeira diferente com base no conteúdo que seria estudado. Conforme obtivesse evolução dos alunos, os tutores do PET-MEC começariam a ensinar matérias mais avançadas (visto que havia atraso no cronograma escolar).

Como forma de avaliar a aplicação de conhecimento de modo geral, é proposto um projeto final para o fim de 2018, com base na confecção de um protótipo de um foguete feito a partir de garrafa pet, tubo de PVC, barbante e bomba de pneu de bicicleta.

Para tentar contornar a situação relacionada à vida cotidiana dos alunos, a estratégia seria ter conversas mais livres, fora dos conteúdos escolares , levar lanches e doces para serem feitas refeições na parte da manhã e fazer gincanas através de perguntas sobre os conhecimentos já adquiridos durante as aulas, tendo os doces como forma de premiação para gerar incentivo.

\subsection{Abordagem}

Foi feita a tentativa de incentivar mais alunos desse período escolar a participarem da proposta do Clubinho de Engenharia no primeiro ano de projeto, pedindo aos professores e a diretoria que avisasse aos alunos sobre como seria o projeto. Porém nem todos entusiasmaramse, a maior parte da turma era formada por meninas (tornando-se unanimidade no segundo semestre do ano de 2018). No ano seguinte, foi adotado que membros do PET-MEC iriam nas escolas para realizar o início das inscrições, além disso, contamos com a presença de alunos que tinham participado do projeto no ano anterior, para falar um pouco de como foi a experiência e, assim, fazer com que o projeto alcançasse mais o interesse dos alunos.

\section{RESULTADOS E DISCUSSÃO}

Tendo ocorrido o início do projeto, em parceria dos alunos do Programa de Educação Tutorial juntamente com o Colégio Estadual Rodolpho Siqueira, foi obtido resultados positivos, 
tanto na experiência com a coordenação do CEDROS, como na vivência com os alunos deste colégio que participaram do Clubinho da Engenharia.

Os membros da equipe ministraram aulas, mais lúdicas e moldáveis, visando o maior número de crianças da turma de $6^{\circ}$ ano. No início, o projeto teve pouca participação dos alunos nas aulas, visto isso, foi necessário mudar os métodos de abordagem direta aos alunos. Sendo assim, buscou-se maior proximidade dos alunos e tutores, para que assim as aulas pudessem ser elaboradas de acordo com o perfil das crianças, bem como pode ser observado maior interesse e participação ativa nas atividades. Dessa forma, foi obtido um resultado muito positivo, uma vez que, houve o ingresso de mais crianças ao decorrer do projeto, o número de crianças inscritas passou de 13 em 2018 para 24 alunos em 2019, aumento de cerca de 84\% no número de inscritos.

\subsection{Da aprendizagem escolar}

Querendo comprovar os resultados dos alunos, a equipe do Clubinho elaborou uma pesquisa com a Coordenação do colégio, onde foi visto mudanças tanto no dia a dia dos alunos, como também nas notas alcançadas nos meios de avaliação aplicados pelos professores da turma que participou do projeto. Segundo dados divulgados pela própria escola, os alunos do $6^{\circ}$ ano atingiram, no ano de 2018, um aproveitamento de $80 \%$ em matemática, $93 \%$ em ciências e $80 \%$ em resoluções de problemas matemáticos. No ano anterior ao início do projeto essas matérias tinham índice de aproveitamento abaixo dos $60 \%$. Não foi possível ter acesso aos dados de 2019. Ademais, houve relatos das crianças que participaram do projeto, onde pode-se ver que o Clubinho teve um ganho significativo para elas.

Na tabela 1 e 2 é possível ver o quão positivo foram os relatos dos alunos do $6^{\circ}$ ano acerca do projeto, sendo estas frases um reflexo geral da turma, que foi acompanhada pelos membros do PET-MEC, durante o Clubinho de Engenharia.

Tabela 1 - Relatos dos Alunos a respeito do "Clubinho de Engenharia"

\begin{tabular}{|c|}
\hline Relatos dos Alunos \\
\hline "Eu só consegui passar de ano por causa da ajuda do Clubinho!" \\
\hline "O clubinho foi muito bom e divertido" \\
\hline "O projeto final que a gente tinha que fazer um foguete foi muito legal" \\
\hline "A gente se divertia muito com eles e a gente conseguiu aprender as matérias de uma \\
forma que não era chata." \\
"A gente aprende não só sobre matemática e ciências. Os monitores muitas vezes falam \\
sobre acontecimentos que fazem parte de história, falam sobre geografia. Algumas vezes, \\
quando chegava em casa do Clubinho, escrevia uma redação sobre tudo o que tinha \\
aprendido e apresentava para a professora de português. Eles também me ajudaram nisso!"
\end{tabular}


Fonte: Autoria própria.

\subsection{Da aplicação do conhecimento no protótipo}

Para a fabricação do protótipo (Figura 1) e apresentação dos projetos, que foi realizada na Universidade Federal Fluminense para os estudantes do primeiro período de Engenharia Mecânica (figura 2), os alunos utilizaram conceitos aprendidos em matemática e ciências durante o ano: geometria, grandezas e medidas, frações, adição, subtração, multiplicação e divisão, sustentabilidade, estados físicos da água (a impulsão do foguete era dado pelo bombeamento de água), atmosfera, noções de astronomia, entre outros assuntos.

Figura 1: teste feito no CEDROS do protótipo do foguete feito pelas crianças

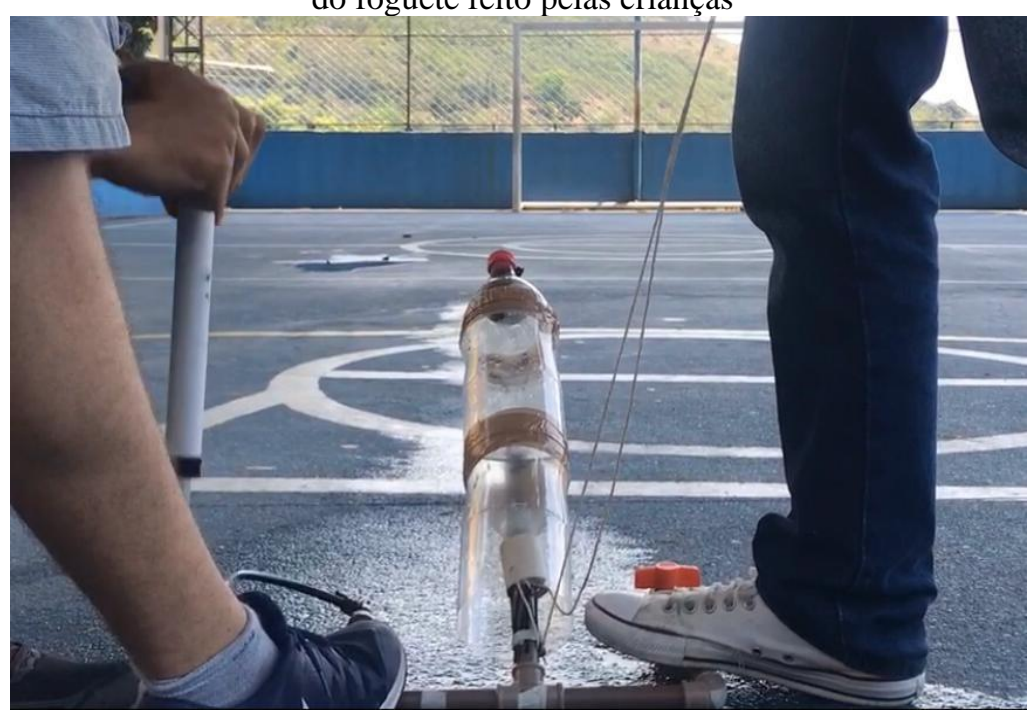

Fonte: Autoria própria.

Figura 2: apresentação do projeto final feita na UFF

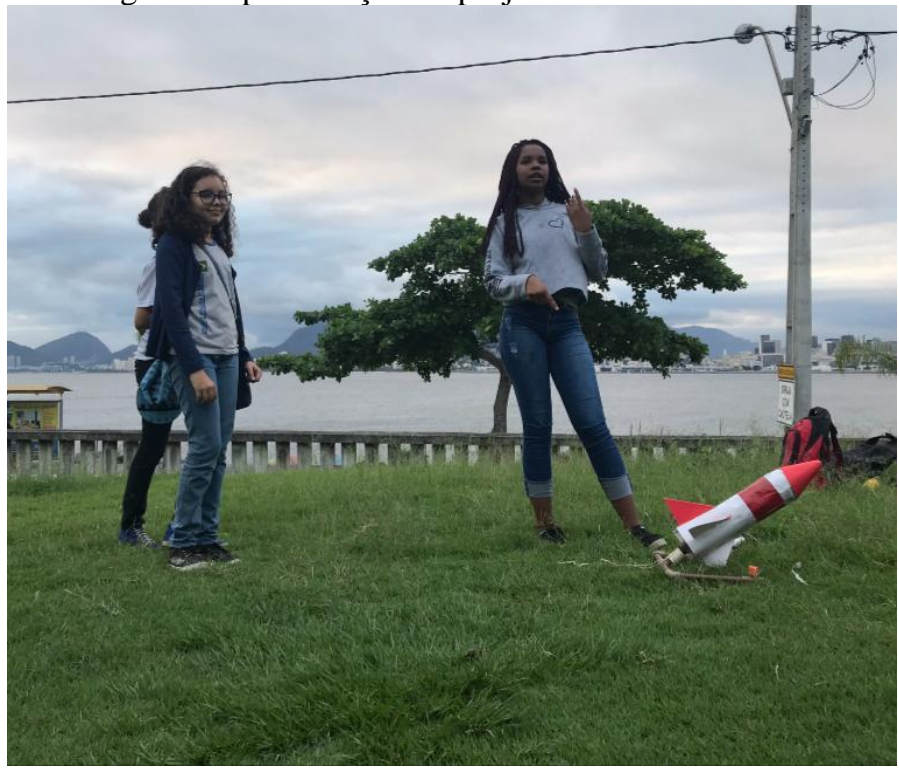

Fonte: Autoria própria. 
O projeto final também motivou os alunos a permanecerem na escola durante o próximo ano. Esta experiência foi positiva não somente no âmbito acadêmico e educacional, como também no lado pessoal de muitos estudantes participantes do projeto. Este tópico, foi mostrado, durante os relatos da direção acerca da parceria entre o CEDROS e o PET-MEC, mostrado na tabela 2.

Tabela 2 - Relatos da direção do CEDROS a respeito do "Clubinho de Engenharia"

\begin{tabular}{|c|}
\hline Relatos dos professores e diretores \\
\hline "Ver as crianças voltando da UFF, após apresentarem o projeto, e no caminho virem \\
comentando sobre os aprendizados que tiveram com o pessoal da Engenharia é muito \\
prazeroso." \\
\hline "O ganho com o Clubinho não foi apenas acadêmico, teve um ganho pessoal entre as \\
crianças. Tivemos relatos das crianças em uma palestra sobre depressão, onde elas \\
disseram que começar a vir no Clubinho os ajudava muito contra a depressão." \\
"As notas e o comportamento dos alunos, que estiveram presentes nas aulas do \\
Clubinho melhoraram bastante, havendo um melhor percentual de aprovação nas matérias \\
onde era visto enorme dificuldades."
\end{tabular}

Fonte: Autoria própria

\subsection{Do estado emocional das crianças}

Nos relatos dos professores e diretores foi mencionado que, durante uma palestra sobre depressão feito por uma psicóloga, no evento "Setembro Amarelo" na escola, algumas crianças relataram experiências e momentos depressivos. Estes jovens são vítimas da doença, uma vez que além dos próprios confirmarem, era atestado através do afastamento com as demais crianças, como também na vestimenta destes mesmos alunos (iam sempre de casaco, mesmo nos dias mais quentes, para evitarem deixar visível as mutilações que faziam). Era claro que as crianças apresentavam problemas tão grandes para a pouca idade, dificuldades que saem da esfera escolar, podendo ser relacionados ao fator econômico e/ou social, como diz Santos (2001). Desta forma, elas eram incapazes de lidar com tais dificuldades, muita das vezes devido a realidade a qual vivem, não tendo o apoio familiar necessário, como mencionado anteriormente.

Ao verem algo novo (como o programa Clubinho de Engenharia, sendo aplicado de uma forma diferente a cada encontro, havendo uma flexibilidade e tendo aulas moldáveis para o perfil da turma), as crianças, que passavam por algumas dificuldades, tinham uma distração para os seus problemas e uma vontade maior de estarem aprendendo e saindo um pouco da realidade (Paula, A. P. et al, 2019.). 
Esta experiência foi positiva não somente no âmbito acadêmico e educacional, como também no lado pessoal de muitos estudantes participantes do projeto. Este tópico, foi mostrado, durante os relatos da direção acerca da parceria entre o CEDROS e o PET-MEC, mostrado na tabela 2.

\section{CONCLUSÃO}

Diante do exposto, é possível concluir que a realização do Clubinho de Engenharia teve impacto positivo na vida das crianças que tiveram a oportunidade de participar. $\mathrm{O}$ principal intuito (facilitar o aprendizado nas matérias de ciências exatas e da natureza) foi alcançado com êxito, uma vez que houve o aumento do rendimento geral da turma nestas disciplinas no ano de 2018, e uma consequente diminuição de defasagem dos alunos nestas séries. Infelizmente, a escola não divulgou os dados referentes ao rendimento dos alunos em 2019.

Também foi alcançado os objetivos paralelos do grupo do Programa de Educação Tutorial, como o de trazer um ambiente diferente e novo para os alunos de uma difícil realidade, onde estes muitas vezes não possuem apoio, incentivo ou até mesmo possibilidades para uma educação diferente daquela básica e comum.

Visto o resultado deste programa, tem-se como projeções futuras a expansão para outras unidades escolares de ensino fundamental público na cidade de Niterói - RJ e proximidades e a continuação no Colégio Estadual Doutor Rodolpho Siqueira (CEDROS) com a nova turma de $6^{\circ}$ ano no ano de 2020.

\section{AGRADECIMENTOS}

Os autores agradecem ao MEC-SESu pelo apoio financeiro ao Programa de Educação Tutorial. Agradecem ainda à direção e coordenação do Colégio Estadual Doutor Rodolpho Siqueira (CEDROS) que permitiram o desenvolvimento do projeto junto aos alunos.

\section{REFERÊNCIAS}

BRASIL. Constituição da República Federativa do Brasil de 1988. Disponível em: http://www.planalto.gov.br/ccivil_03/constituicao/constituicao.htm. Acesso em: 18 abr. 2020.

ECKSTEIN, Zvi; WOLPIN, Kenneth. Why youths drop out of high school: the impact of preferences, opportunities, and abilities. Econometrica, v. 67, n. 6, p.1295-1339, 1999. 
Ideb. Índice de Desenvolvimento da Educação Básica. Disponível em: http://idebescola.inep.gov.br/ideb/consulta-publica. Acesso em: 17 mar 2020

INEP. Censo Escolar da Educação Básica 2017. Disponível em: http://portal.inep.gov.br/artigo/-/asset_publisher/B4AQV9zFY7Bv/content/inep-divulgadados-ineditos-sobre-fluxo-escolar-na-educacao-basica/21206. Acesso em: 21 abr 2019.

Paula, Andreia Piza de et al. Transição do $5^{\circ}$ para $06^{\circ}$ ano no ensino fundamental: processo educacional de reflexão e debate. Disponível em: http://www.opet.com.br/faculdade/revistapedagogia/pdf/v8/v8-artigo-3-TRANSICAO-DO-5-PARA-O-6-ANO-NO-ENSINO-

FUNDAMENTAL.pdf . Acesso: 25 de abr 2019

Santos, Antonio Hamilton dos. et al. As dificuldades enfrentadas para o ensino de ciências naturais em escolas municipais do sul de Sergipe e o processo de formação continuada. Disponível em: http://educere.bruc.com.br/ANAIS2013/pdf/9474_6573.pdf . Acesso: 28 de abr 2019.

Silva, Josimere Nunes. Confecção de jogos matemáticos na sala de de apoio a aprendizagem com alunos do $\mathbf{6}^{\circ}$ ano do ensino fundamental. Disponível em http://www.diaadiaeducacao.pr.gov.br/portals/cadernospde/pdebusca/producoes_pde/2014/20 14_unespar-campomourao_mat_pdp_josimere_nunes_da_silva.pdf . Acesso: 28 abr 2019.

\title{
Clubinho de Engenharia: a Playful Approach to Science and Mathematics Teaching
}

\begin{abstract}
The difficulty on the transition for the second part of elementary education II is something very evident and that seeks to be softened with the work of the Engineering Club. The students of the Programa de Educação Tutorial Federal Fluminense University aim to increase students' interest in learning and studying the subjects passed by the teachers. The methodology used was to introduce practical and playful activities involving the disciplines of Science and Mathematics so that could show a more friendly and close side of the students' lives to attract them. The games aim to create a greater interest in the subjects and to make them more excited as they enter a new phase of academic life. Therefore, it reduces the gap and difficulty of the students in the corresponding curricular contents.
\end{abstract}

Key-words: extension, science, Mathematics, Elementary School. 